\title{
AVALIAÇÃO DE UM CURSO DE ENSINO SUPERIOR ATRAVÉS DA SATISFAÇÃO/INSATISFAÇÃO DISCENTE
}

\author{
Saulo Aparecido de Souza* \\ JOSÉ NILSON REINERT**
}

Recebido em: 05 de junho de 2009 Aprovado em: 17 de setembro de 2009

\begin{abstract}
* Graduado em Administração pela Universidade Federal de Mato Grosso do Sul. Atualmente é mestrando em Administração pela mesma Instituição. Atua principalmente no tema: Pesquisa no Ensino da Administração. E-mail: souza.saulo@hotmail.com.

** Dr. em Administração de Empresas pela EAESP/FGV e Pós-doutorado na New School for Social Research, USA. É professor da Universidade Federal de Mato Grosso do Sul e atua principalmente nos temas: Administração Geral, Gestão Universitária e Pesquisa no Ensino da Administração. E-mail: icaro.phenix@ uol.com.br.
\end{abstract}

Resumo: O propósito deste estudo foi analisar a avaliação de um curso de graduação através da identificação dos fatores que geram satisfação e insatisfação por parte de seus estudantes e, também, comparar os resultados entre as modalidades de ensino presencial e a distância. O questionário empregado deixou o estudante livre para indicar espontaneamente aquilo que o satisfaz ou insatisfaz. Em seguida, os resultados foram analisados por meio da técnica análise de conteúdo. Os resultados indicam que, na avaliação dos estudantes, os principais fatores determinantes da satisfação e da insatisfação com o curso estão relacionados com a estrutura curricular, o corpo docente e o ambiente social. Foram encontradas diferenças significativas na comparação entre as modalidades de ensino pesquisadas. A estrutura física e algumas características do curso foram consideradas pouco importantes para a avaliação dos cursos pelos estudantes.

Palavras-chave: Satisfação discente. Avaliação de cursos superiores. Avaliação discente.

\section{EVALUATION OF A HIGHER EDUCATION PROGRAM THROUGH STUDENT SATISFACTION/DISSATISFACTION}

\begin{abstract}
This study analyzed the evaluation of a higher education program by identifying factors that cause satisfaction and dissatisfaction according to higher education students' views and also compared the results between distance learning and traditional classroom students. The questionnaire provided an opportunity for the students to spontaneously indicate the factors that caused satisfaction and dissatisfaction. The results were then analyzed using content analysis technique. The results indicate that students evaluate curriculum structure, faculty, and social environment as the main determinants of satisfaction and dissatisfaction concerning to the program. Significant differences were found in the comparison between traditional classroom and distance learning formats. Department infrastructure and some characteristics of the program were considered unimportant for the students' program evaluation.
\end{abstract}

Key words: Student satisfaction. Evaluation of higher education programs. Student evaluation.

\section{INTRODUÇÃO}

Peter Drucker, quando se reporta ao aprendizado vitalício, afirma que este deve ser "atraente e trazer em si uma grande satisfação" (1993, p. 156). Neste trabalho, a satisfação discente é considerada um aspecto importante, não apenas 
no aprendizado vitalício, mas em qualquer forma de aprendizado, inclusive nos cursos de graduação.

A satisfação também assume papel relevante na avaliação discente de cursos superiores, por resultar de um julgamento formulado a partir da realidade percebida. A avaliação, por meio da satisfação, deveria ser mais intensamente considerada nos cursos de graduação em administração, pois existe grande demanda por esta área no país, em parte porque se acredita que possibilite uma colocação mais fácil no mercado de trabalho, gerando otimismo nos estudantes.

No caso da Universidade Federal de Mato Grosso do Sul (UFMS), são oferecidos cursos de graduação em administração na modalidade presencial e a distância $(\mathrm{EaD})$. A fim de conhecer melhor o ponto de vista do estudante e obter informações para melhorar a qualidade do ensino e da aprendizagem, além de tornar o aprendizado mais atrativo, considerou-se relevante ouvir a manifestação de seu corpo discente na área de administração, através da identificação dos fatores percebidos como geradores de satisfação e insatisfação. Também foram feitas análises comparativas entre as modalidades de ensino presencial e a distância.

Assim, espera-se contribuir para o estabelecimento de estratégias que possam melhorar a aprendizagem dos estudantes. Espera-se, também, contribuir com os docentes e as coordenações dos cursos nos esforços para a busca de uma maior satisfação dos estudantes, de modo a diminuir o desencontro entre as expectativas dos mesmos e o que a instituição oferece. O não atendimento dessas expectativas pode gerar desempenho mais baixo, integração mais reduzida, insucesso e, em alguns casos, até mesmo o abandono do curso. (SCHLEICH; POLYDORO; SANTOS, 2006)

\section{SATISFAÇÃO, NECESSIDADES E EXPECTATIVAS}

A forma mais ampla de satisfação é a satisfação com a vida. Esta pode ser entendida como o resultado de domínios, como família, trabalho e saúde (RODE, 2004). Nessa perspectiva, a satisfação vem recebendo tentativas de explicação por meio de diferentes abordagens.

Para Archer (1997), a satisfação decorre do atendimento ou da eliminação de uma necessidade. Isso ocorre quando um fator (externo) diminui a tensão da necessidade (interna) elevando o nível de satisfação. Assim, a necessidade funciona como um elemento motivador para a busca de seu correspondente fator de satisfação. 
Outra abordagem é o paradigma da expectância/desconfirmação que, por sua vez, oferece bases para a compreensão da relação entre as expectativas e a satisfação do estudante (ATHIYAMAN, 1997; APPLETON-KNAPP; KRENTLER, 2006). Nesse sentido, a satisfação pode ser definida como a experiência de realização de uma expectativa (HOM, 2002). O paradigma abrange quatro construtos: expectativas, desempenho, desconfirmação e satisfação. A desconfirmação nasce das discrepâncias entre expectativas anteriores e desempenho atual (realidade percebida). Então três possibilidades podem ocorrer: nenhuma desconfirmação resulta quando o desempenho atual ocorre como o esperado; desconfirmação positiva ocorre quando o desempenho atual é superior ao esperado; e desconfirmação negativa ocorre quando o desempenho atual é menor do que o esperado.

Adesconfirmação positiva produz satisfação, enquanto que a desconfirmação negativa produz insatisfação. Desse modo, o estudante forma suas expectativas sobre as aulas antes do seu início e depois faz sua desconfirmação com base no desempenho percebido. É importante ressaltar que as expectativas formadas anteriormente influenciam os julgamentos posteriores sobre o desempenho observado que levarão à satisfação ou insatisfação. (OLIVER; BURKE, 1999)

A medição da satisfação, porém, possui uma série de dificuldades. Entre elas a relatividade excessiva, por ser uma característica psicológica do indivíduo; o conceito de satisfação possuir diferentes significados para diferentes pesquisadores; e o fato de o grau de satisfação variar ao longo do tempo com a obtenção de novas informações. (BEBER, 1999)

\section{SATISFAÇÃO DISCENTE}

Um estudante não deve ser considerado simplesmente como cliente, mas como um verdadeiro parceiro no processo de aprendizagem. O estudante parceiro não é um "aluno produto" a ser processado como matéria-prima, nem um "aluno cliente" do lado de fora do balcão de atendimento, mas um participante ativo no processo de ensino/aprendizagem que se comporta como um sócio em relação à escola. (REINERT; REINERT, 2005)

A satisfação discente é influenciada por diversos fatores. Numa tentativa de organizar esses fatores, Appleton-Knapp e Krentler (2006), a partir do resultado de várias pesquisas de satisfação, classificaram estes fatores em pessoais (relacionados ao estudante) e institucionais (relacionados à experiência educacional).

Dentre os fatores que influenciam positivamente a satisfação dos estudantes, estão: amigos do grupo (KANAN; BAKER, 2006); identificação pessoal com 
a área e aspectos externos ao aluno, como mercado de trabalho favorável e boa estrutura do curso (BARDAGI; LASSANCE; PARADISO, 2003); boa resposta às necessidades e expectativas em geral (APPLETON-KNAPP; KRENTLER, 2006; PETRUZZELLIS; D'UGGENTO; ROMANAZZI, 2006); habilidades, conhecimentos, estratégias, postura e formas de interação do professor com a turma (CAMARGOS; CAMARGOS; MACHADO, 2006; DOUGLAS; DOUGLAS; BARNES, 2006); e percepção do ensino como algo proveitoso. (DOUGLAS; McCLELLAND; DAVIES, 2008)

Dentre os fatores que influenciam negativamente a satisfação, estão: desapontamento com a má organização e falha geral em atender expectativas (PETRUZZELLIS; D’UGGENTO; ROMANAZZI, 2006); despreparo e pouco compromisso com as turmas por parte do corpo docente (CASTILLO; LOPES, 1996); e falta de disponibilidade e prontidão para responder por parte do corpo docente (DOUGLAS; DOUGLAS; BARNES, 2006). Há ainda fatores que não afetam expressivamente a satisfação, como atividades extracurriculares esportivas e sociais no campus. (YIN; LEI, 2007)

Resultados de outras pesquisas mostram que não existem grandes diferenças nos níveis de satisfação entre estudantes de cursos presenciais e de cursos a distância (POOL, 1996; BOWER; KAMATA, 2000). Porém, há evidências de que cursos a distância que, inicialmente, geram altas expectativas otimistas, podem resultar em baixa satisfação com a posterior desconfirmação negativa das expectativas. (VAMOSI; PIERCE; SLOTKIN, 2004)

Os fatores de satisfação podem variar consideravelmente, dependendo do modo pelo qual o estudante vê a si mesmo e seu ambiente. Trata-se da percepção em relação ao ensino, que pode ser entendida como a forma do aluno visualizar a realidade no cotidiano e formar juízo de valor baseado na sua leitura de ações, gestos, discursos, normas e nas atitudes de funcionários, direção e professores (CAMARGOS; CAMARGOS; MACHADO, 2006). Essa percepção se torna mais crítica com o passar do tempo devido ao maior conhecimento sobre os serviços prestados pela universidade e com o maior envolvimento do estudante com esses serviços, o que torna mais precisa a formação da satisfação. (PETRUZZELLIS; D'UGGENTO; ROMANAZZI, 2006; NASSER; KHOURY; ABOUCHEDID, 2008)

A avaliação, portanto, não é estática ao longo do tempo porque os estudantes reavaliam continuamente suas opiniões anteriores com base em novas informações (APPLETON-KNAPP; KRENTLER; 2006). Assim, o nível de satisfação pode variar conforme mais informações são consideradas para a análise e julgamento do curso. Além disso, quando os estudantes fazem avaliação 
da satisfação, no final do curso, as lembranças de suas expectativas iniciais são distorcidas, pois o nível de satisfação atual influencia na declaração das expectativas anteriores. (APPLETON-KNAPP; KRENTLER, 2006)

No complexo de fatores que formam a satisfação com a experiência educacional, os mais importantes são as expectativas (POOL, 1996). As expectativas atribuídas à universidade são positivamente relacionadas com a satisfação e podem, como decorrência, aumentar ou enfraquecer a atitude formada anteriormente sobre as aulas (ATHIYAMAN, 1997). Para explicar esse processo, Athiyaman propõe uma sequência para a desconfirmação do estudante. Primeiro, ele forma uma atitude sobre a universidade com base nas informações iniciais disponíveis. Ao entrar na universidade, acontece a desconfirmação das expectativas quando compara a atitude inicial com o ambiente e o curso percebido. Dessa comparação resulta satisfação ou insatisfação e, então, o estudante faz uma revisão da sua atitude inicial sobre a universidade. Como se vê, essa sequência é uma aplicação da teoria da expectância/desconfirmação ao contexto educacional.

Estudantes que experimentam falhas nos serviços em sala de aula ficam insatisfeitos e demonstram forte propensão a compartilhar as informações negativas sobre suas experiências (DAVIS; SWANSON, 2001). Desse modo, apenas uma experiência desagradável teria seu efeito multiplicado entre os colegas, influenciando suas avaliações e podendo ter um efeito mais amplo. Para diminuir a possibilidade de insatisfação, Gremler e McCollough (2002) sugerem oferecer garantias de satisfação aos estudantes. A garantia teria um efeito positivo na avaliação dos professores e do curso como um todo.

Como se observa, a avaliação da experiência percebida pelo estudante, das características do curso e do desempenho do corpo docente são fatores frequentemente presentes na formação da satisfação com o curso.

\section{METODOLOGIA}

Esta pesquisa consistiu em uma investigação qualitativa de caráter exploratório, descritivo e estudo de caso, realizada com a população de graduandos dos cursos de administração da UFMS. Segundo Gil (1999), o estudo de caso pode ser utilizado em pesquisas exploratórias e em pesquisas descritivas, se mostrando apropriado para este estudo.

Os cursos foram escolhidos pelo critério de acessibilidade. Participaram da pesquisa 356 estudantes, sendo 139 do curso presencial diurno, 138 do presencial noturno e 79 alunos da modalidade a distância, no segundo semestre 
de 2007. Os estudantes apresentaram idade média de 25,2 anos e 68\% deles trabalhavam. O curso presencial concentra-se na cidade de Campo Grande, enquanto que os cinco pólos de ensino a distância localizam-se nas cidades de Água Clara, Campo Grande, Nova Andradina, São Gabriel do Oeste e Rio Brilhante, todas no estado de Mato Grosso do Sul.

Para investigar o nível de satisfação dos estudantes quanto a serviços e determinados atributos dos cursos ou mesmo de universidades, algumas escalas e questionários foram desenvolvidos (por exemplo, SCHLEICH; POLYDORO; SANTOS, 2006; NASSER; KHOURY; ABOUCHEDID, 2008). Porém, Aldridge e Rowley (1998) consideram ser desafiador desenvolver um instrumento de mensuração da satisfação que possa levar em conta a natureza diversa dos estudantes, já que cada um pode desfrutar de níveis diferentes de experiência em cada área da instituição de ensino. Assim, o método empregado nesta pesquisa procurou deixar o estudante livre para indicar espontaneamente o que considerasse relevante para sua satisfação e insatisfação com o curso.

Os estudantes responderam às questões abertas: "O que mais lhe agrada no curso?" e "O que mais the desagrada no curso?". As respostas foram analisadas por meio da técnica análise de conteúdo. Segundo Bardin (2004, p. 37), este instrumento de análise de comunicações procura "obter, por procedimentos sistemáticos e objetivos de descrição do conteúdo das mensagens, indicadores (quantitativos ou não) que permitam a inferência de conhecimentos relativos às condições de produção/recepção (variáveis inferidas) destas mensagens".

Foram identificados temas ou sentidos completos (unidades de registro) nas manifestações, que receberam classificação do tipo temática (ou análise categorial). Um tema é uma asserção sobre determinado assunto e é considerado como a mais útil unidade de registro em análise de conteúdo (FRANCO, 2003). Num primeiro momento, o material foi pré-analisado com o intuito de se manter os primeiros contatos com as respostas. Em seguida, o material foi relido e a partir das respostas mais frequentes foram definidas subcategorias. Numa terceira etapa, as respostas foram classificadas dentro das subcategorias criadas previamente, de acordo com suas similaridades. Por fim, as subcategorias foram agrupadas em categorias, também de acordo com suas similaridades.

As manifestações sobre "O que mais lhe agrada no curso?" fizeram menção a temas que foram agrupados em seis categorias representativas dos fatores percebidos como geradores de satisfação: a) estrutura curricular; b) corpo docente; c) ambiente social; d) características do curso; e) infra-estrutura; e f) outro ou não respondeu. As manifestações sobre "O que mais lhe desagrada no 
curso?" resultaram também nestas mesmas cinco categorias de resposta, mas como geradoras dos fatores de insatisfação.

\section{RESULTADOS}

Os resultados são apresentados a partir das frequências das categorias criadas para os três cursos considerados: curso presencial diurno, curso presencial noturno e curso modalidade a distância. As frequências são relativas ao número total de estudantes, de modo a contar o quanto cada categoria foi registrada independentemente das demais. Isso permite ao somatório ultrapassar 100\%. É importante ressaltar que as respostas tabuladas tiveram um padrão bastante regular, seja ao longo dos quatro anos dos cursos presenciais, seja entre os pólos, no caso do curso na modalidade a distância.

\subsection{Curso presencial diurno}

Conforme se observa na Figura 1, a satisfação dos estudantes do curso presencial diurno está concentrada na categoria estrutura curricular, que aparece com frequência de $73 \%$ em relação ao total de respondentes. Dentre as subcategorias componentes dessa categoria, as mais citadas foram: satisfação com alguma matéria, novos conhecimentos ou habilidades adquiridos, multidisciplinaridade e outros aspectos da estrutura curricular.

A segunda categoria mais citada como fator de satisfação foi o corpo docente, em $22 \%$ dos casos. Decompondo essa categoria, observa-se a frequente menção a algum professor. A terceira categoria mais citada está relacionada com o ambiente social (em 17\%). Aparecem com menor expressividade as características do curso (6\%) e a infra-estrutura (5\%).

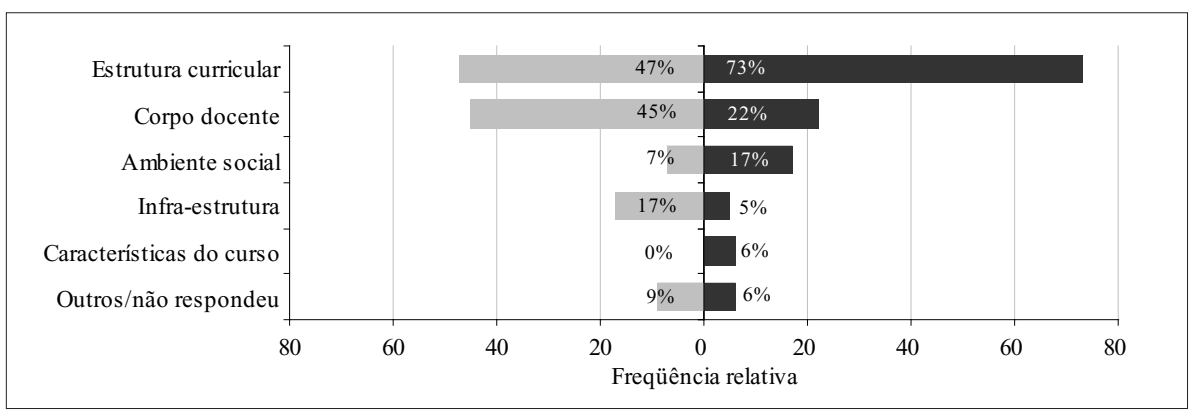

Figura 1 - Avaliação dos fatores de satisfação e insatisfação no curso presencial diurno. Fonte: Elaborado pelos autores. 
Quanto à insatisfação, os estudantes fizeram referência, sobretudo, à estrutura curricular, em $47 \%$ dos casos, e ao corpo docente, em $45 \%$ dos casos. A principal causa de insatisfação com a estrutura curricular é a falta de atividades ou aulas práticas, seguida pela insatisfação com alguma matéria, além de outros aspectos. Já a categoria corpo docente, quando desmembrada em suas subcategorias, apresenta insatisfação com algum professor, com a didática e com os métodos empregados em sala de aula. Como terceira causa de insatisfação está a infra-estrutura, com 17\%. Com menor frequência, aparece o ambiente social (7\%).

Observa-se, na Figura 1, uma clara concentração nas duas primeiras categorias, estrutura curricular e corpo docente, tanto como causa de satisfação como de insatisfação, o que evidencia a importância desses dois componentes no ensino, segundo a avaliação dos estudantes.

\subsection{Curso presencial noturno}

De maneira semelhante ao constatado no curso presencial diurno, a satisfação no curso presencial noturno também está concentrada na estrutura curricular, com frequência de $70 \%$ nas respostas (Figura 2). Os principais componentes dessa categoria foram: alguma matéria, novos conhecimentos ou habilidades e multidisciplinaridade.

A segunda categoria mais citada como motivo de satisfação no curso noturno é o corpo docente, em $32 \%$ dos casos, sendo que esta é formada principalmente pela satisfação com algum professor. Em terceiro lugar aparece o ambiente social (24\%), constituído, basicamente, pela subcategoria envolvimento com colegas. Em menores proporções estão as características do curso (7\%) e a infra-estrutura (4\%).

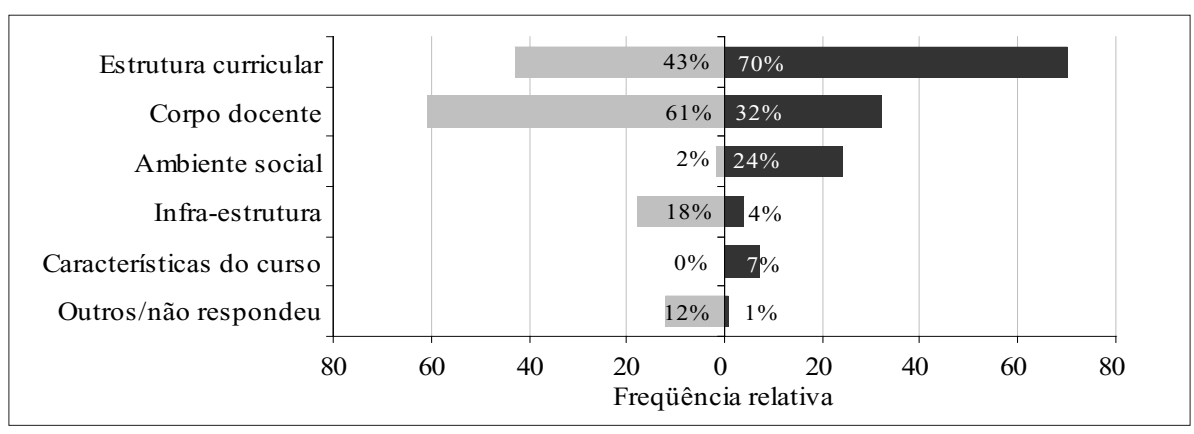

Figura 2 - Avaliação dos fatores de satisfação e insatisfação no curso presencial noturno. Fonte: Elaborado pelos autores. 
A insatisfação dos estudantes do curso presencial noturno recai fortemente em aspectos do corpo docente, presentes em $61 \%$ das respostas. Desmembrandoa, tem-se que a maior parte dessa insatisfação é devido a alguns professores e à didática e métodos empregados. A segunda categoria mais citada para a insatisfação é a estrutura curricular, com frequência de 43\%, composta, principalmente, pelas subcategorias insatisfação com alguma matéria e a falta de aulas ou atividades práticas. Com menores frequências, aparecem as categorias infra-estrutura (18\%) e ambiente social (2\%).

\subsection{Curso modalidade a distância}

De acordo com a Figura 3, a percepção de satisfação no curso na modalidade a distância é devida, principalmente, ao corpo docente, que aparece em $71 \%$ das respostas. Quando decomposta, tem-se que as subcategorias mais frequentes estão relacionadas à didática empregada (principalmente a flexibilidade do curso) e aos professores como um todo.

Depois do corpo docente, aparece a categoria estrutura curricular, em $42 \%$ das respostas, tendo como itens mais expressivos os novos conhecimentos e as habilidades. Com menores frequências figuram: ambiente social (24\%), características do curso (4\%) e infra-estrutura (1\%).

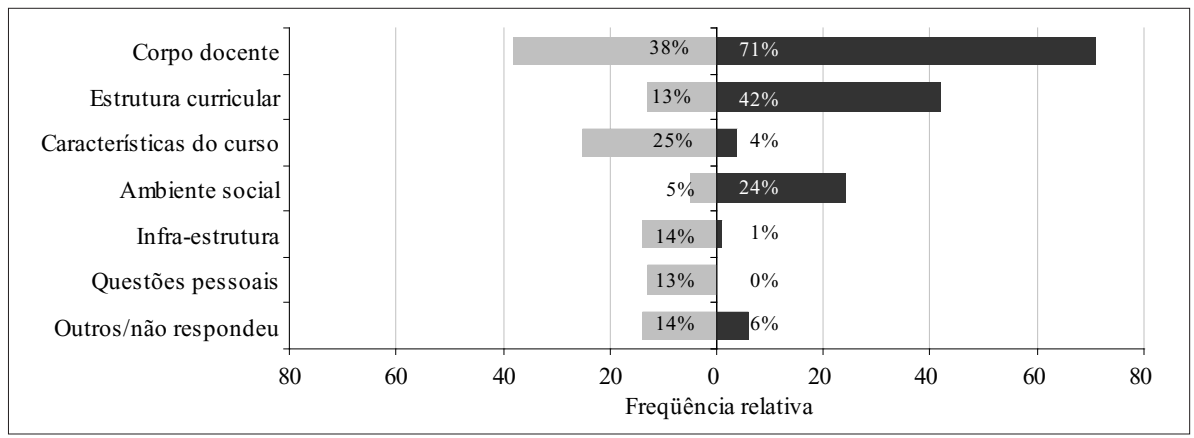

Figura 3 - Avaliação dos fatores de satisfação e insatisfação no curso a distância. Fonte: Elaborado pelos autores.

No que tange à insatisfação, ainda de acordo com a Figura 3, no curso a distância há algumas características peculiares, sendo que as respostas levaram à criação de uma categoria particular para englobar questões pessoais dos estudantes, como a dificuldade para estudar sozinho ou a distância de sua residência em relação ao pólo. As respostas que denotam insatisfação estão 
mais bem distribuídas entre as categorias de análise, figurando, em primeiro lugar, o corpo docente, com frequência de $38 \%$, cujas principais subcategorias consistem na demora para resposta e baixa disponibilidade dos professores ou tutores. A segunda categoria mais frequente corresponde às características do curso, com $25 \%$ das respostas. Nessa categoria são comuns menções à falta de aulas presenciais e à baixa interação entre os estudantes. Como terceira e quarta causas de insatisfação aparecem infra-estrutura e questões pessoais, ambas com $14 \%$ de frequência. Por fim, estão estrutura curricular (13\%) e ambiente social (5\%).

\section{ANÁLISE E DISCUSSÃO}

O propósito deste estudo foi analisar a avaliação de um curso superior através da identificação dos fatores que geram satisfação e insatisfação por parte dos estudantes, comparando os resultados entre as modalidades de ensino. A partir dos 356 questionários devolvidos, resultaram 947 unidades de registro, das quais 489 relatavam o que mais satisfaz e 458 o que mais insatisfaz. Num primeiro momento, esse resultado indica que é um pouco mais fácil para o estudante se recordar de algo agradável do que de algo desagradável e que cada um mencionou em média pouco mais de um item por resposta.

De maneira geral, os cursos têm como maior fonte de satisfação a estrutura curricular, sendo que a maior expressividade se deu com relação a alguma matéria. Foram comuns entre os estudantes respostas como: "Algumas matérias, como Administração Financeira, Planejamento Empresarial e todas as matérias específicas do curso". Outra forma frequente de resposta, relacionada com a estrutura curricular, diz respeito às habilidades e aos novos conhecimentos adquiridos com o curso, como esta resposta: "O pensamento sistêmico que as disciplinas proporcionam".

Algumas matérias também são bastante mencionadas como fonte de insatisfação quando o assunto é estrutura curricular. São frequentes comentários sobre disciplinas consideradas desnecessárias, difíceis ou sem aplicação prática. $\mathrm{Na}$ educação a distância, ocorre uma inversão dessa categoria com a categoria corpo docente, a mais citada como fonte de insatisfação. Porém, a tônica é semelhante e as habilidades conquistadas com o curso são os pontos mais lembrados.

Parece não surpreender o fato de a estrutura curricular aparecer como uma das categorias mais citadas, tanto como motivo de satisfação quanto de insatisfação. Afinal, trata-se daquilo com que mais contato se tem no curso, o objeto sobre o qual estudante e professor trabalham durante todo o tempo. Assim como 
existem conteúdos com que o estudante se identifica mais e conteúdos com que se identifica menos, o papel de disciplinas optativas na estrutura curricular parece importante como alternativas de opção. Nesse sentido, um currículo mais livre e flexível, que permita aos estudantes centrar em seus próprios interesses, habilidades e vocações, seria desejável para que pudessem se diferenciar e se adequar melhor às necessidades do mundo contemporâneo (CRISTOFOLINI; REINERT, 2005). O estudante poderia participar do processo de formação, não estando tão preso ao modelo de "grade" com enfoque unicamente disciplinar e sequenciado, que pode ser, em alguns casos, motivo maior de insatisfação.

Outra fonte recorrente de insatisfação quanto à estrutura curricular, especialmente nos cursos presenciais, diz respeito à falta de atividades práticas. Esse ponto de vista dos estudantes é compreensível, na medida em que os cursos não têm atividades complementares, como empresa júnior, parcerias ou outras atividades que aproximem mais os estudantes da realidade prática do mercado de trabalho. A esse respeito, Mintzberg e Gosling (2003) lembram que a educação gerencial significa pouco para aqueles que não experimentaram a prática. Para os autores, o aprendizado ocorre quando os conceitos encontram as experiências por meio das reflexões. Uma alternativa para a interação entre teoria e prática poderiam ser os estágios supervisionados, que podem contribuir para a maturidade intelectual e aproximar o estudante da excelência formacional. (OLIVEIRA, 2007)

Nos cursos presenciais, diurno e noturno, mas não na modalidade a distância, a segunda categoria que aparece, tanto como fonte de satisfação quanto de insatisfação, é o corpo docente. Nesta categoria, alguns professores foram citados com grande frequência como causadores de satisfação, nas três turmas. Notou-se que os docentes eram indicados tanto como aspectos de satisfação quanto de insatisfação no curso e, então, numa segunda análise, foram detectados padrões nas respostas, como a palavra "alguns", que sempre aparecia antes da palavra "professores". Ou seja, alguns agradam e outros não. Isso pode ser exemplificado pela resposta de um estudante denotando satisfação neste quesito: "Alguns professores, em matérias próprias da administração, que possuem alto grau de conhecimento e conseguem transmitir estes conhecimentos em sala de aula".

Nos cursos presenciais, certos professores são vistos como experientes, detentores de muitos conhecimentos e hábeis na transmissão dos mesmos. Por outro lado, outros já não têm a mesma avaliação positiva. A insatisfação maior com esta última parcela é com a percepção de falta de experiência, domínio dos conteúdos ministrados e dificuldade para transmitir conhecimentos. Algumas respostas associam mais esse perfil deficiente aos professores substitutos, aos 
professores voluntários, ou aos professores de outros departamentos (que não o mais diretamente vinculado com a formação), que ministram aulas basicamente nos dois primeiros anos de curso. Os cursos presenciais, como um todo, apresentam alta taxa de professores substitutos e voluntários (43\%) e tal situação talvez tenha contribuído para que fosse encontrada essa distinção dentro da categoria corpo docente.

Esta constatação é consistente com os estudos de Gursoy e Umbreit (2005) e de DeShields, Kara e Kaynak (2005), por sugerirem que, embora haja um número significativo de variáveis que possam levar à satisfação ou insatisfação, o fator que mais influencia os estudantes é o desempenho do corpo docente e as aulas. Talvez isso possa ser, em parte, explicado pelo fato de docentes percebidos como mais "quentes" serem mais bem avaliados do que os "frios", não só quanto à personalidade, mas também quanto às habilidades instrucionais. (WIDMEYER; LOY, 1988)

Para os estudantes do curso a distância, os elementos que mais geram satisfação na categoria corpo docente são a flexibilidade para o cumprimento das demandas do curso e também alguns professores. Estudos anteriores já confirmaram a ligação entre flexibilidade percebida e satisfação do estudante de curso a distância (ARBAUGH, 2000). O corpo docente, como motivo de insatisfação para o curso a distância, diferentemente dos cursos presenciais, é composto basicamente por aspectos didáticos. São frequentes as menções à ausência dos docentes (ou tutores) para orientação, demora para responder questionamentos, falta de orientação em algumas disciplinas e desorganização do curso.

Essas dificuldades, em geral, também se relacionam com a estrutura do curso que, no período em que foi realizada a pesquisa, ainda era experimental. Foi visível, quando da realização da pesquisa, que ainda existia certa distância entre professor e aluno. A esse respeito, Arbaugh (2001) aponta que os esforços dos instrutores para diminuir a distância entre eles e os estudantes são importantes preditores do aprendizado e satisfação com o curso. Além disso, fornecer informações e feedback sistêmico para grupos virtuais aumenta seu desempenho, motivação e satisfação, impactando especialmente nos membros menos motivados do grupo. (GEISTER; KONRADT; HERTEL, 2006)

O terceiro item mais citado nos cursos como importante para a satisfação dos estudantes relaciona-se com o ambiente social. Essa categoria inclui citações tanto de interações aluno-professor quanto de interações entre alunos e, também, a satisfação em poder participar de discussões e debates em sala de aula, como nesta resposta: "A interação com os professores e com os colegas, a 
troca de conhecimentos". Mais uma vez, não existem grandes diferenças entre as modalidades de ensino presencial e a distância. $\mathrm{O}$ fator que mais insatisfaz nesta categoria é o desinteresse e desrespeito de alguns colegas para com os demais. Assim mesmo, na educação a distância, que implica mais horas de estudo individualizado, os estudantes acreditam que a interação melhora a experiência de aprendizado e que maior interação é preferível à menor interação. (VAMOSI; PIERCE; SLOTKIN, 2004)

Por fim, com baixa presença nas respostas, aparecem infra-estrutura e características do curso. Infra-estrutura é mais citada como causa de insatisfação do que de satisfação e se refere principalmente à administração do curso. Quanto às características do curso, cumpre notar que este estudo encontrou resultados semelhantes aos de Castillo e Lopes (1996) a respeito da baixa frequência de respostas mencionando a gratuidade do ensino superior público como um aspecto favorável. Talvez isso ocorra devido à crença de que o curso gratuito é um direito e, como tal, não precisa ser valorizado.

Além das categorias analisadas, fez-se necessário adicionar para a modalidade a distância uma categoria específica para abarcar a insatisfação expressa com algumas questões pessoais, como dificuldade para estudar sozinho, organizar horários de estudo, bem como a distância entre a residência e os pólos de apoio presencial. Apesar de esta modalidade superar a barreira da distância geográfica e proporcionar flexibilidade de horários, ela exige, também, a habilidade do autodidatismo. No entanto, essa habilidade ainda não é bem desenvolvida na cultura latino-americana e muitos não confiam em um sistema educacional sem professores presentes. (DÍAZ BORDENAVE, 1987). Talvez o desenvolvimento dessa habilidade possa ser o maior desafio a ser superado pelo estudante de um curso a distância.

\section{CONCLUSÕES}

Esta pesquisa procurou analisar a avaliação de um curso superior, nas modalidades presencial e a distância, por meio dos fatores de satisfação e insatisfação manifestados por seus estudantes. Para tanto, foram levantadas as opiniões dos mesmos, que, em seguida, foram analisadas por meio da técnica análise de conteúdo.

A partir da análise das manifestações, as categorias estrutura curricular e corpo docente emergiram como fatores que mais influenciam tanto a satisfação quanto a insatisfação dos estudantes com o curso. Em seguida, aparecem outros dois fatores com menores frequências e gerando avaliações diferentes por parte 
dos estudantes: ambiente social, como causa de satisfação, e infra-estrutura, como causa de insatisfação. No curso a distância, emergiram, ainda, alguns elementos ligados à insatisfação com características do curso.

É interessante observar que alguns fatores são determinantes tanto de satisfação quanto de insatisfação, variando de acordo com a percepção que o estudante possui do curso. Isso reforça o caráter complexo da avaliação, que, no âmbito educacional, refere-se a fenômenos humanos e sociais, articulando múltiplos referentes e perspectivas. (DIAS SOBRINHO, 2008)

Na comparação entre modalidades, os fatores que mais satisfazem os estudantes dos três cursos diferem quanto às frequências e ordem de importância das categorias. Na média entre os cursos presenciais, os principais fatores de satisfação são estrutura curricular e corpo docente. No curso a distância, há uma inversão, sendo o corpo docente o principal fator de satisfação, seguido por estrutura curricular. Neste caso, existem diferenças expressivas, especialmente na categoria corpo docente. Nos cursos presenciais, há mais referência a algum professor, enquanto que, no curso a distância, há mais referência à didática empregada, que, no caso, tem grande relação com o formato do próprio curso.

Também são conferidas diferenças entre os fatores que mais causam insatisfação. Nos cursos presenciais, figuram o corpo docente e a estrutura curricular, ao passo que, no curso a distância, aparecem o corpo docente e as características do curso. Este resultado permite sugerir que o corpo docente é percebido como muito importante para a insatisfação em ambas as modalidades, mas por razões distintas. Enquanto nos cursos presenciais ocorre insatisfação, sobretudo com relação a alguns professores e sua didática em sala de aula, no curso a distância ocorre pela demora para resposta e baixa disponibilidade de professores e tutores.

O ambiente social não diferiu expressivamente entre as três turmas estudadas, tanto como fonte de satisfação quanto de insatisfação. De certa maneira, isso poderia ser pouco esperado para a educação a distância que, pela sua própria natureza, deveria demandar menor interação entre os colegas e, consequentemente, ser menos mencionada. Os resultados indicam que a interatividade também é importante para no referido curso, apesar da distância física entre aluno-professor e entre os próprios alunos. 


\section{REFERÊNCIAS}

ALDRIDGE, S.; ROWLEY, J. Measuring customer satisfaction in higher education. Quality Assurance in Education, Bingley, v. 6, n. 4, p. 197-204, 1998.

APPLETON-KNAPP, S. L.; KRENTLER, K. A. Measuring student expectations and their effects on satisfaction: the importance of managing student expectations. Journal of Marketing Education, Newbury Park, v. 28, p. 254-264, 2006.

ARBAUGH, J.B. Virtual classroom characteristics and student satisfaction with internet-based MBA courses. Journal of Management Education, Newbury Park, v. 24, n. 1, p. 32-54, 2000.

. How Instructor immediacy behaviors affect student satisfaction and learning in web-based courses. Business Communication Quarterly, Newbury Park, v. 64, n. 4, p. 42-54, 2001.

ARCHER, E. R. Mito da motivação. In: BERGAMINI, C. W. CODA, R. Psicodinâmica da vida organizacional: motivação e liderança. São Paulo: Atlas, 1997. p. 23-46.

ATHIYAMAN, A. Linking student satisfaction and service quality perceptions: the case of university education. European Journal of Marketing, Bingley, v. 31, n. 7, p. 528-540, 1997.

BARDAGI, M. P.; LASSANCE, M. C. P.; PARADISO, Â. C. Trajetória acadêmica e satisfação com a escolha profissional de universitários em meio de curso. Revista Brasileira de Orientação Profissional, Ribeirão Preto, v. 4, n. 1-2, p. 153-166, 2003.

BARDIN, L. Análise de conteúdo. Lisboa: Edições 70, 2004.

BEBER, S. J. N. Estado atual dos estudos sobre a satisfação do consumidor. In: ENCONTRO DA ASSOCIAÇÃO NACIONAL DE PÓS-GRADUAÇÃO E PESQUISA EM ADMINISTRAÇÃO, 23., Foz do Iguaçu. Anais... Foz do Iguaçu: ENANPAD, 1999. 1 CD-ROM. 
BOWER, B. L.; KAMATA, A. Factors influencing student satisfaction with online courses. Academic Exchange Quarterly, Stuyvesant Falls, p. 52-56, 2000 .

CASTILLO, J. A. B.; LOPES, H. E. G. Avaliação do processo educacional num curso de Administração: o ponto de vista dos alunos. In: ENCONTRO NACIONAL DOS CURSOS DE GRADUAÇÃO EM ADMINISTRAÇÃO, 7., 1996, Florianópolis. Anais... Florianópolis: ANGRAD, 1996. 1 CDROM.

CAMARGOS, M. A.; CAMARGOS, M. C. S.; MACHADO, C. J. Análise das preferências de ensino de alunos de um curso superior de administração de Minas Gerais. Revista de Gestão da USP, São Paulo, v. 13, n. 2, p. 1-14, 2006.

CRISTOFOLINI, A. REINERT, J. N. A liberdade na formação curricular do estudante de graduação. In: COLÓQUIO INTERNACIONAL SOBRE GESTIÓN UNIVERSITARIA EN AMÉRICA DEL SUR, 5., 2005, Mar del Plata. Anais... Mar del Plata: Gestão Universitária na América do Sul, 2005.

DAVIS, J. C.; SWANSON, S. Navigating satisfactory and dissatisfactory classroom incidents. Journal of Education for Business, Washington, v. 76, n. 5, p. 245-250, 2001.

DeSHIELDS JR, O. W.; KARA. A.; KAYNAK, E. Determinants of business student satisfaction and retention in higher education: applying Herzberg's two-factor theory. International Journal of Educational Management, Bradford, v. 19, n. 2, p. 128-139, 2005.

DIAS SOBRINHO, J. Avaliação educativa: produção de sentidos com valor de formação. Avaliação: Revista da Avaliação da Educação Superior, Campinas; Sorocaba, v. 13, n. 1, p. 193-207, 2008.

DÍAZ BORDENAVE, J. E. Teleducação ou educação a distância: fundamentos e métodos. Petrópolis: Vozes, 1987.

DOUGLAS, J.; DOUGLAS, A.; BARNES, B. Measuring student satisfaction at a UK university. Quality Assurance in Education, Bingley, v. 14, n. 3, p. 251-267, 2006. 
DOUGLAS, J.; McCLELLAND, R.; DAVIES, J. The development of a conceptual model of student satisfaction with their experience in higher education. Quality Assurance in Education, Bingley, v. 16, n. 1, p. 19-35, 2008.

DRUCKER, P. F. A sociedade pós-capitalista. São Paulo: Pioneira, 1993.

FRANCO, M. L. P. B. Análise de conteúdo. Brasília: Plano, 2003.

GEISTER, S.; KONRADT, U.; HERTEL, G. Effects of process feedback on motivation, satisfaction, and performance in virtual teams. Small Group Research, Newbury Park, v. 37, n. 5, p. 459-489, 2006.

GIL, A. C. Métodos e técnicas de pesquisa social. São Paulo: Atlas, 1999.

GREMLER, D. D.; McCOLLOUGH, M. A. Student satisfaction guarantees: an empirical examination of attitudes, antecedents, and consequences. Journal of Marketing Education, Newbury Park, v. 24, n. 2, p. 150-160, 2002.

GURSOY, D.; UMBREIT, W. T. Exploring students' evaluations of teaching effectiveness: what factors are important? Journal of Hospitality \& Tourism Research, Newbury Park, v. 29, n. 1, p. 91-109, 2005.

HOM, W. Applying customer satisfaction theory to community college planning of student services. IJournal, Sacramento, v. 2, set. 2002. Disponível em: < http://www.ijournal.us/issue_02/ij_issue02_WillardHom_01. htm>. Acesso em: 18 jan. 2009.

KANAN, H. M.; BAKER, A. M. Student satisfaction with an educational administration preparation program: a comparative perspective. Journal of Educational Administration, Bingley, v. 44, n. 2, p. 159-169, 2006.

MINTZBERG, H.; GOSLING, J. Educando administradores além das fronteiras. Revista de Administração de Empresas, São Paulo, v. 43, p. 29-43, 2003.

NASSER, R. N.; KHOURY, B.; ABOUCHEDID, K. University students' knowledge of services and programs in relation to satisfaction: a case study of a private university in Lebanon. Quality Assurance in Education, Bingley, v. 16, n. 1, p. 80-97, 2008. 
OLIVEIRA, A. C. C. Estágio supervisionado no contexto das instituições de ensino superior: aportes reflexivos acerca da sua inserção nos cursos de administração. Revista ANGRAD, Rio de Janeiro, v. 8, n. 1, p. 73-91, 2007.

OLIVER, R. L.; BURKE, R. R. Expectation processes in satisfaction formation: a field study. Journal of Service Research, Newbury Park, v. 1, n. 3, p. 196-214, 1999.

PETRUZZELLIS, L.; D’UGGENTO, A. M.; ROMANAZZI, S. Student satisfaction and quality of service in Italian universities. Managing Service Quality, Bingley, v. 16, n. 4, p. 349-364, 2006.

POOL, P. Teaching via interactive television: an examination of teaching effectiveness and student satisfaction. Journal of Education for Business, Washington, v. 72, p. 78-81, 1996.

REINERT, J. N.; REINERT, C. Estudante não é cliente: é parceiro. In: ENCONTRO DA ASSOCIAÇÃO NACIONAL DE PÓS-GRADUAÇÃO E PESQUISA EM ADMINISTRAÇÃO, 29., 2005, Brasília. Anais Eletrônicos... Brasília: ANPAD, 2005. 1 CD-ROM.

RODE, J. C. Job satisfaction and life satisfaction revisited: a longitudinal test of an integrated model. Human Relations, Newbury Park, v. 57, n. 9, p. 1205-1230, 2004.

SCHLEICH, A. L.; POLYDORO, S. A. J.; SANTOS, A. A. Escala de satisfação com a experiência acadêmica de estudantes do ensino superior. Avaliação Psicológica, Itatiba, v. 5, n. 1, p. 11-20, 2006.

VAMOSI, A. R.; PIERCE, B. G.; SLOTKIN, M. H. Distance learning in an accounting principles course: student satisfaction and perceptions of efficacy. Journal of Education for Business, Washington, p. 360-366, 2004.

WIDMEYER, W. N.; LOY, J. W. When you're hot, you're hot! Warm-cold effects in first impressions of persons and teaching effectiveness. Journal of Educational Psychology, Memphis, v. 80, n. 1, p. 118-121, 1988.

YIN, D.; LEI, S. A. Impacts of campus involvement on hospitality student achievement and satisfaction. Education, Mobile, v. 128, n. 2, p. 282-293, 2007. 